\title{
PULMONARY CYSTS FOLLOWING INGESTION OF HOUSEHOLD PARAFFIN
}

\author{
BY \\ ANDREW SKARBEK \\ From the North Cambridgeshire Hospital, Wisbech
}

(RECEIVED FOR PUBLICATION MARCH 17, 1955)

This is the rather unusual case of a small boy who developed an acute pneumonia with multiple cystic cavities in the lungs after drinking household paraffin or kerosene. There was complete resolution in a few weeks, and a striking absence of physical signs in the chest.

The boy, aged $2 \frac{1}{2}$ years, was brought to the North Cambridgeshire Hospital, Wisbech, on June 18, 1954. The mother gave the following history.

On the day before admission the child drank about three-quarters of a one-pound jam jar filled with 'Aladdin' pink paraffin. The child was given $1 \frac{1}{2}$ teaspoonfuls of 'syrup of figs' and a mineral drink, and remained quite well until the evening, when it was noticed that he looked pale and apathetic, his breath smelling strongly of paraffin. He did not vomit or cough that day. The following morning he looked ill, very pale, and he refused food, though not complaining of any pain or discomfort. The past history revealed that the boy was the sixth child of the family, weighing $7 \mathrm{lb} .5 \mathrm{oz}$. at birth. There were no complications of pregnancy, delivery or infancy. The family history did not reveal anything of interest.

On admission his temperature was $102^{\circ} \mathrm{F}$., pulse 140 , and respirations were 45 . No abnormality was found in the respiratory system except that his respirations were grunting and the breath sounds harsh. The child was rather lethargic, pale, slightly cyanosed, and clearly distressed and dyspnoeic. He passed a large offensive motion which blistered his buttocks. Haemoglobin was $12 \cdot 8 \mathrm{~g}$., the white cell count 12,000 (55\% polymorphs, $40 \%$ lymphocytes and $5 \%$ monocytes).

A radiograph taken on that day presented the appearance of bilateral pulmonary collapse affecting probably the right middle lobe, the lingula and both lower lobes (Fig. 1). The child was put in an oxygen tent and treated with 250,000 units of crystalline penicillin four-hourly. His temperature and respiration rate gradually settled down during the next three days, and he appeared to be making a satisfactory recovery. On June 23 , the fifth day after admission, the temperature rose again to $103^{\circ} \mathrm{F}$., the pulse to 140 and the respirations to 45 . The child again looked acutely ill and distressed. Aureomycin was given, 100 mg., six-hourly.
After this his temperature gradually settled down, and within the next four or five days his general condition improved, although he appeared very ill for about two weeks. He remained in an oxygen tent all that time. His appetite gradually improved and he gained some weight. A radiograph taken 15 days after admission showed a cavity in the right lung, at the site of the lower zone collapse in the previous radiograph. It was round,

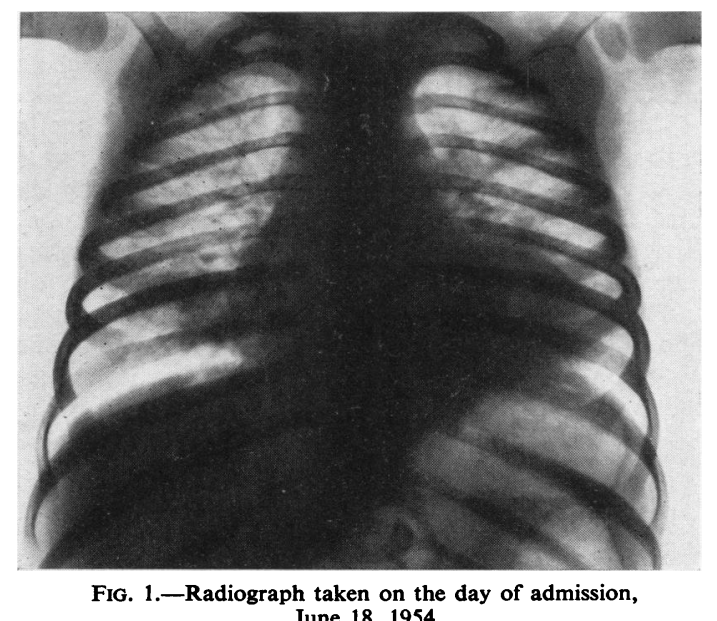

$4 \mathrm{~cm}$. in diameter, the thickness of the wall being $4 \mathrm{~mm}$. There was no fluid level.

In the left lung there was a system of cavities in the middle and lower zones, occupying the site of the former collapse, of similar appearance to that described above. Right and left lateral films confirmed multiple cavities in the right middle lobe and left lingula and lower lobes (Figs. 2 and 3).

A blood examination taken on the eighteenth day after admission showed a haemoglobin of $12 \cdot 2 \mathrm{~g}$. with 3,290,000 R.B.C.s, 5,000 W.B.C.s (polymorphs 26\%, lymphocytes $68 \%$, monocytes $6 \%$ ). A radiograph on that day showed a fluid level in the right basal cavity which by a week later had shrunk to about $1 \mathrm{~cm}$. in diameter. The fluid level remained. The cavity was 

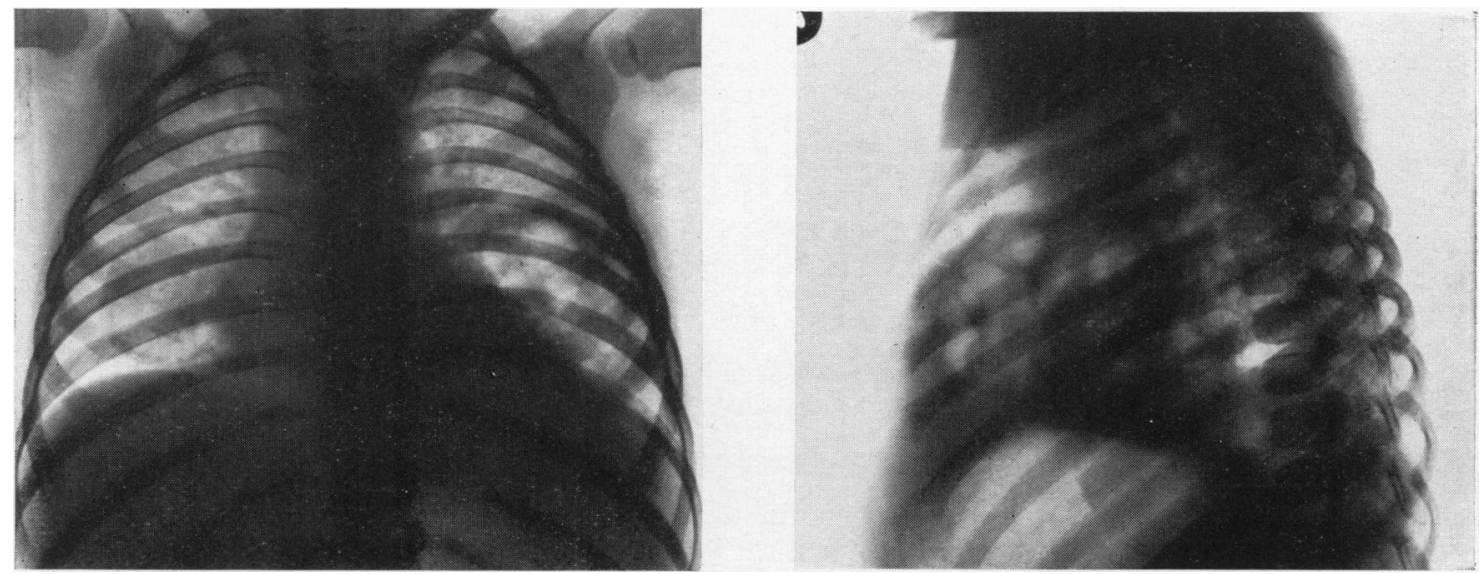

Figs. 2 and 3.-Radiographs taken 15 days after admission on July 2, 1954, showing multiple cavities.

surrounded by atelectasis of the medial segment of the middle lobe.

In the left lung there was marked reduction in the size of the cavities, and no fluid levels.

The child remained apyrexial, and no abnormal physical signs were found except for a few rales at both bases. He was treated with daily postural drainage and percussion.

Subsequent radiographs showed a further reduction in the size of the cavity in the right lung, clearing in the lower zone of both lungs, and finally complete disappearance of the cystic spaces. He was transferred one month after admission to a convalescent home. On his return, three weeks later, radiographs showed further clearing and re-expansion of the collapsed part of the lower lobes. The child remained well, gaining weight, and a film taken two months after admission showed some right basal collapse but no cystic changes.

\section{Discussion}

The literature, especially from America, contains a number of references to kerosene poisoning and pneumonia.

Lesser, Weens and McKey (1943) found in their series of experiments using rabbits that pulmonary manifestations in these animals were more likely to be due to aspiration of the kerosene into the lungs than to absorption via the intestinal tract.

Experiments on dogs and rabbits by Richardson and Pratt-Thomas (1951) have indicated that, assuming conditions in these animals to be comparable to children weighing $50 \mathrm{lb}$., then, provided that aspiration does not occur, a volume in excess of a pint would have to be swallowed to prove fatal. The patient described here swallowed almost a jam jar full of kerosene, and would thus seem to have drunk a potentially lethal dose. On the other hand, however, if only slightly more than a teaspoonful were aspirated, severe pneumonia with an almost certain fatal outcome would result.

Theoretically one can suppose that paraffin can reach the lungs via the intestine. Frazer, Shulman and Stewart (1944) have shown that fine emulsions may be absorbed from the rat's intestine in particulate form, pass along the lacteals to the thoracic duct and then through the great veins into the right heart and lungs.

It might be argued that the cause of pulmonary complications following the drinking of kerosene is in fact aspiration, the child reacting to the unpleasant taste by choking and vomiting. While this is clearly possible, it is not in fact true that the taste of kerosene is at all unpleasant, as anyone who has tried it will agree.

In this case, however, as the large quantity of kerosene ingested could itself account for the severity of the subsequent pneumonia, and as this did not develop until 24 hours later, it does not seem necessary to invoke aspiration as one of the mechanisms of the disease.

Deichmann, Kitzmiller, Witherup and Johansmann (1944) described histological findings in kerosene pneumonia. These consist of oedema and vascular congestion with focal areas of acute interstitial inflammation and haemorrhages. The alveoli contain inflammatory exudates consisting of fluid fibrin and white blood cells and foreign body giant cells. In extreme cases the entire tracheobronchial tree is filled with this exudate and the mucosa of smaller radicles shows ulceration in places.

Radiological appearances vary from small patchy densities in the costophrenic angles to the large mottled densities of severe cases. The pulmonary 
changes are seen more commonly bilaterally, and are usually more pronounced in the base of the right lung. The changes are more consistent with those of hyperaemia or oedema than of pneumonitis.

Changes in the lung were observed to occur rapidly after kerosene ingestion, and resolved usually after two weeks. In spite of the fact that kerosene in contact with the body tissues may result in fibrosis, complete resolution with no evidence of permanent tissue damage is usually found.

The remarkable feature in the case described is the formation of cysts in the lungs. It is considered that the $x$-ray appearances were caused by tension cyst formation rather than by destruction of lung tissue. This view was based on the rapidity with which recovery occurred and on the fact that no appreciable increase in the white blood cell count was found. There is no reference in the literature to tension cyst formation following kerosene pneumonia. Hodson and Neill (1948) described six cases in which air-containing spaces were found occurring in a variety of pulmonary lesions; staphylococcal pneumonia, lobar pneumonia, fluidcontaining cysts (probably congenital), localized pneumonic consolidation and in one case consolidation and collapse without pyrexia. In the present case the radiological appearances may have been a direct result of paraffin ingestion, or to secondary infection such as the staphylococcal infection described by Hodson and Neill. The latter supposition may be supported by the rapidity with which the condition subsided with antibiotics.

\section{Summary}

A case is described of bilateral pulmonary tension cysts in a $2 \frac{1}{2}$-year-old child after drinking kerosene.

My thanks to Dr. B. W. Powell for permission to publish this case and to him and Dr. Downes for their criticism and helpful suggestions.

\section{REFERENCES}

Deichman, W. B., Kitzmiller, K. V., Witherup, S. and Johansmann, R (1944) Ann. intern. Med., 21, 803.

Hodson, C. I. and Neill, C. A. (1948) Archives of Disease in Childhood, 23, 144.

Frazer, A. C., Schulman, J. H. and Stewart, H. C. (1944). J. Physiol. Lond., 103, 306.

Lesser, L. I., Weens, H. S. and McKey, J. D. (1943). J. Pediat., $23,352$.

Richardson, J. A. and Pratt-Thomas, H. R. (1951). Amer. J. med. Sci., 221, 531. 